\title{
RP-HPLC Method for Simultaneous Estimation of Cefepime Hydrochloride and Tazobactam Sodium in Bulk and Pharmaceuticals
}

\author{
Sagar R. Tamboli and Dipak D. Patil \\ Department of Quality Assurance, H. R. Patel Institute of Pharmaceutical Education and Research, Karvand Naka, \\ Shirpur 425405, India \\ Correspondence should be addressed to Dipak D. Patil; dipakpatil888@rediffmail.com
}

Received 31 May 2013; Revised 10 August 2013; Accepted 24 August 2013

Academic Editor: Ghada M. Hadad

Copyright (C) 2013 S. R. Tamboli and D. D. Patil. This is an open access article distributed under the Creative Commons Attribution License, which permits unrestricted use, distribution, and reproduction in any medium, provided the original work is properly cited.

A precise, accurate, sensitive and robust RP-HPLC method was developed for cefepime hydrochloride and tazobactam sodium in bulk and pharmaceutical formulation. Chromatographic separation was achieved on PrincetonSPHER-100 C-18 column $(250 \mathrm{~mm} \times 4.6 \mathrm{~mm}$ i.d., $5 \mu \mathrm{m})$ at ambient temperature. A binary mobile phase consisting of $25 \mathrm{mM}$ potassium dihydrogen phosphate buffer, pH 6.2 and acetonitrile $(94: 6, \mathrm{v} / \mathrm{v})$ was delivered through a column at a flow rate of $1 \mathrm{~mL} / \mathrm{min}$. Measurement was performed at a wavelength $210 \mathrm{~nm}$. The method was linear over the concentration range of $4-24 \mu \mathrm{g} / \mathrm{mL}\left(r^{2}=0.9977\right)$ for cefepime and $0.5-3.0 \mu \mathrm{g} / \mathrm{mL}\left(r^{2}=0.9974\right)$ for tazobactam. The percentage content found for cefepime was $101.12 \pm 0.49$ and for tazobactam was $101.33 \pm 1.17$ in the pharmaceutical formulation. The method was validated for linearity, precision, accuracy, sensitivity and robustness as per ICH Q2 (R1) guideline.

\section{Introduction}

Cefepime hydrochloride (CEFE) is fourth-generation, semisynthetic, broad spectrum, cephalosporin antibiotic for parenteral administration. Chemically, it is 1-[[(6R, 7R)-7-[2-(2Amino-4-thiazolyl)-glyoxylamido]-2-carboxy-8-oxo-5-thia1-azabicyclo [4.2.0] oct-2-en-3-yl] methyl]-1-methylpyrrolidinium chloride, $7^{2}$-(Z)-(O-methyloxime), monohydrochloride, monohydrate (Figure 1). CEFE is a zwitterionic oxymino $\beta$-lactam with an amino-thiazole side chain, which enhances the ability of CEFE to penetrate rapidly the outer cell membrane of gram-negative bacteria. CEFE used in the treatment of moderate-to-severe infections such as pneumonia, uncomplicated urinary tract infections, skin and soft tissue infections, intra-abdominal infections and febrile neutropenia.

Tazobactam sodium (TAZO) is chemically known as (2S, 3S, 5R)-3-methyl-7-oxo-3-(1H-1, 2, 3-triazol-1-ylmethyl)4-thia-1-azabicyclo [3.2.0] heptane-2-carboxylic acid 4,4dioxide (Figure 1). TAZO is semisynthetic parenteral penicillin. TAZO is a $\beta$-lactamase inhibitor with a broad spectrum of antibacterial activity against most gram positive, gram negative aerobic bacteria and anaerobic bacteria.

Megapime XP is a sterile combination of CEFE and TAZO available as a dry powder for injection. The fixed dose combination of CEFE and TAZO is used parenterally for the treatment of moderate to severe infection caused by or suspected of being caused by susceptible $\beta$-lactamases producing bacteria, while CEFE alone would be ineffective. CEFE and TAZO combination used for the treatment of uncomplicated and complicated urinary tract infection, uncomplicated skin and skin structure infection and complicated intra-abdominal infection.

A literature survey revealed that several liquid chromatography methods had been reported for the determination of CEFE alone [1-4] as well as for stability and degradation study [5-9].

CEFE in combination with other drugs had been estimated by numerous liquid chromatography methods $[1,10-$ 19].

TAZO was also successfully determined by HPLC [20-26]. 


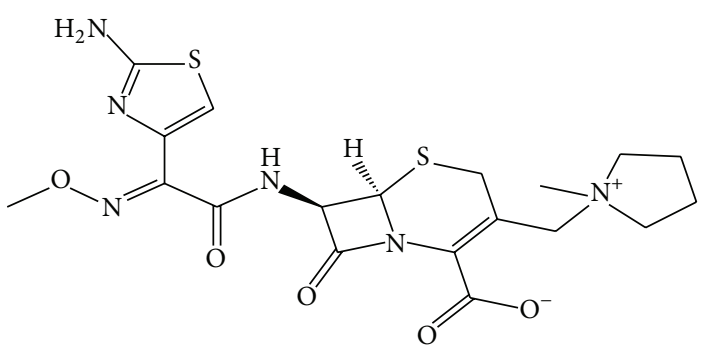

(a)

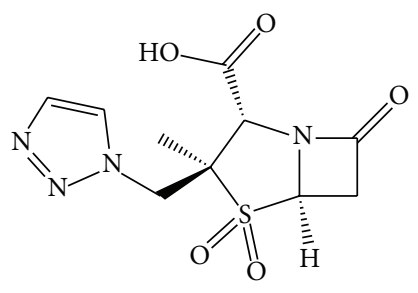

(b)

FIgURE 1: Chemical structure of (a) cefepime (b) tazobactam.

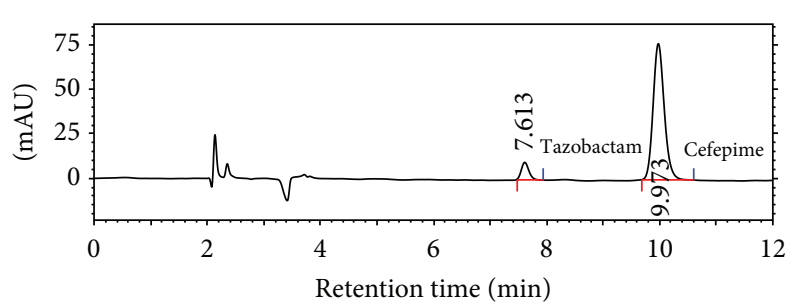

FIgUre 2: Typical chromatogram of CEFE and TAZO.

Till date no chromatographic method is available for simultaneous estimation of CEFE and TAZO in combination. So, it was thought to develop simple RP-HPLC method for simultaneous estimation of CEFE and TAZO in bulk as well as in pharmaceutical formulation.

\section{Experimental}

2.1. Instrumentation. Chromatographic separation was performed using chromatography system equipped with the Agilent G1315D diode array detector. Ez-Chrome Elite software was employed for data collecting and processing.

2.2. Reagents and Materials. CEFE and TAZO reference standard (RS) was obtained from Alembic LTD, Vadodara, India. Megapime XP, a fixed dose combination of CEFE and TAZO was purchased from the local pharmacy. Acetonitrile (HPLC grade) and potassium dihydrogen phosphate of AR grade were obtained from Merck, Mumbai.

2.3. Chromatography Condition. Chromatographic separation was performed on PrincetonSPHER-100 C-18 stainless steel column with dimensions of $250 \times 4.6 \mathrm{~mm}$ i.d., $5 \mu \mathrm{m}$ particle size. A binary mobile phase consisting of $25 \mathrm{mM}$ potassium dihydrogen phosphate buffer, $\mathrm{pH} 6.2$ and acetonitrile $(94: 6, \mathrm{v} / \mathrm{v})$ was delivered through a column at a flow rate of $1 \mathrm{~mL} / \mathrm{min}$. The phosphate buffer, $\mathrm{pH} 6.2$ and acetonitrile were filtered separately through a $0.45 \mu \mathrm{m}$ membrane filter paper, mixed. The mobile phase was degassed before use. HPLC analysis was performed at ambient temperature with detection at $210 \mathrm{~nm}$. The injection volume was $20 \mu \mathrm{L}$.

\subsection{Preparation of Standard Stock Solution}

2.4.1. Standard Stock Solution of CEFE $(100 \mu \mathrm{g} / \mathrm{mL})$. An accurately weighed quantity of powder equivalent to $10.0 \mathrm{mg}$ of CEFE was transferred to $100 \mathrm{~mL}$ volumetric flask. The drug was dissolved and diluted to the mark with distilled water.

2.4.2. Standard Stock Solution of TAZO $(10 \mu \mathrm{g} / \mathrm{mL})$. An accurately weighed quantity of powder equivalent to $10.0 \mathrm{mg}$ of TAZO was transferred to $100 \mathrm{~mL}$ volumetric flask. The drug was dissolved and diluted to the mark with distilled water. An aliquot of about $10.0 \mathrm{~mL}$ was transferred to $100 \mathrm{~mL}$ volumetric flask and diluted with distilled water.

\subsection{Analysis of Laboratory Mixture}

2.5.1. Standard Solution $(100 \mu \mathrm{g} / \mathrm{mL}$ of CEFE and $12.5 \mu \mathrm{g} / \mathrm{mL}$ of TAZO). An accurately weighed quantity of $80.0 \mathrm{mg}$ CEFE and $10.0 \mathrm{mg}$ TAZO was transferred to $100.0 \mathrm{~mL}$ volumetric flask. The volume was adjusted up to the mark to obtain $800.0 \mu \mathrm{g} / \mathrm{mL}$ of CEFE and $100.0 \mu \mathrm{g} / \mathrm{mL}$ of TAZO. Then aliquot of about $12.5 \mathrm{~mL}$ of above CEFE and TAZO solution was diluted up to $100.0 \mathrm{~mL}$.

2.5.2. Working Standard Solution $(12 \mu \mathrm{g} / \mathrm{mL}$ of CEFE and $1.5 \mu \mathrm{g} / \mathrm{mL}$ of TAZO). An aliquot of about $1.2 \mathrm{~mL}$ stock solution of 100 and $12.5 \mu \mathrm{g} / \mathrm{mL}$ of solution of CEFE and TAZO was transferred to $10.0 \mathrm{~mL}$ volumetric flask. The volume was adjusted up to the mark with water to obtain $12 \mu \mathrm{g} / \mathrm{mL}$ of CEFE and $1.5 \mu \mathrm{g} / \mathrm{mL}$ of TAZO. Each working standard solution was analyzed six times as per the optimized chromatographic condition. The chromatogram of CEFE and TAZO has been shown in Figure 2.

\subsection{Assay of Marketed Formulation}

2.6.1. Sample Solution $(100 \mu \mathrm{g} / \mathrm{mL}$ of CEFE and $12.5 \mu \mathrm{g} / \mathrm{mL}$ of TAZO). A quantity of megapime XP powder of about $19.8 \mathrm{mg}$ (equivalent to $10 \mathrm{mg}$ of CEFE and $1.25 \mathrm{mg}$ of TAZO) was transferred to $100.0 \mathrm{~mL}$ volumetric flask. The powder was dissolved in water and sonicated for $10 \mathrm{~min}$. The volume was made up to the mark with water.

2.6.2. Working Sample Solution $(12 \mu \mathrm{g} / \mathrm{mL}$ of CEFE and $1.5 \mu \mathrm{g} / \mathrm{mL}$ of TAZO). An aliquot of about $1.2 \mathrm{~mL}$ of sample 
TABLE 1: Analysis of marketed formulation.

\begin{tabular}{lcc}
\hline Parameters & CEFE & TAZO \\
\hline Amount taken $(\mu \mathrm{g} / \mathrm{mL})$ & 12.0 & 1.5 \\
Amount found $(\mu \mathrm{g} / \mathrm{mL})$ & 12.09 & 1.5199 \\
$\%$ Assay \pm SD $(n=6)$ & $101.12 \pm 0.49$ & $101.33 \pm 1.17$ \\
$\%$ RSD & 0.48 & 1.15 \\
\hline
\end{tabular}

solution of $100 \mu \mathrm{g} / \mathrm{mL}$ CEFE and $12.5 \mu \mathrm{g} / \mathrm{mL}$ TAZO was transferred to $10.0 \mathrm{~mL}$ volumetric flask. The volume was adjusted up to the mark to obtain $12 \mu \mathrm{g} / \mathrm{mL}$ of CEFE and $1.5 \mu \mathrm{g} / \mathrm{mL}$ of TAZO. The sample was analyzed six times as per the optimized chromatographic condition.

2.7. Validation. The method was validated for system suitability, linearity, range, precision, accuracy, limit of detection (LOD), limit of quantitation (LOQ), specificity and robustness as per ICH Q2 (R1) guidelines [27]. System suitability parameters of developed HPLC method were determined by analyzing standard working solution. Chromatographic parameters such as retention time, asymmetry, theoretical plates, capacity factor and resolution were determined. Linearity was calculated with six concentration levels of CEFE and TAZO. Precision was measured both intraday and interday. In the intraday study, concentration of CEFE and TAZO was analyzed three times on the same day at an interval of an hour. In an interday study, the concentration of CEFE and TAZO was analyzed on three different days. Accuracy was studied by the measurement of recovery at three different levels such as $80 \%, 100 \%$ and $120 \%$ of the amount expected in the formulation. LOD and LOQ of the method was studied to detect the lowest amount of analyte and quantitative determination of analyte in a sample, respectively. Robustness study was carried out statistically by using design expert software [28].

\section{Results}

In the present work, a RP-HPLC method was developed and validated for the simultaneous estimation of CEFE and TAZO in bulk and pharmaceutical dosage form. The final optimized chromatographic conditions were PrincetonSPHER-100 C-18 column $(250 \mathrm{~mm} \times 4.6 \mathrm{~mm}$ i.d., $5 \mu \mathrm{m})$ as stationary phase eluted with a binary mobile phase consisting of $25 \mathrm{mM}$ potassium dihydrogen phosphate buffer, $\mathrm{pH} 6.2$ and acetonitrile $(94: 6, \mathrm{v} / \mathrm{v})$. The flow rate of mobile phase was $1 \mathrm{~mL} / \mathrm{min}$ with detection wavelength $210 \mathrm{~nm}$. By using optimized chromatographic conditions, CEFE and TAZO were eluted at $9.97 \mathrm{~min}$ and $7.61 \mathrm{~min}$, respectively (Figure 2).

3.1. Assay of Marketed Formulation. The assay result of CEFE and TAZO in pharmaceutical dosage form was comparable with the value claimed on the vial. The percentage content found for CEFE was 101.12 \pm 0.49 and for TAZO was $101.33 \pm$ 1.17 (Table 1).
TABLE 2: Results of validation parameters.

\begin{tabular}{lcc}
\hline Parameter & CEFE & TAZO \\
\hline System suitability parameters $(n=5)$ & & \\
Retention time $(\mathrm{min}) \pm \%$ RSD & $10.49 \pm 0.68$ & $7.69 \pm 0.83$ \\
Capacity factor $\pm \%$ RSD & $3.19 \pm 0.35$ & $2.07 \pm 0.84$ \\
Theoretical plate \pm \% RSD & $10505 \pm 1.11$ & $12957 \pm 0.65$ \\
Asymmetry factor $\pm \%$ RSD & $1.02 \pm 0.92$ & $0.99 \pm 1.24$ \\
Linearity study & & \\
Linearity range $(\mu \mathrm{g} / \mathrm{mL})$ & $4-24$ & $0.5-3.0$ \\
Slope & 73730 & 48802 \\
Intercept & 27477 & 2327.9 \\
Correlation coefficient $\left(r^{2}\right)$ & 0.9977 & 0.9974 \\
Precision $(n=3)$ & & \\
Repeatability (\% RSD) & 0.92 & 1.09 \\
Interday (\% RSD) & 0.27 & 0.54 \\
Intraday (\% RSD) & 0.51 & 0.29 \\
Accuracy $(n=3)$ & & \\
80\% $\pm(\%$ RSD) & $102.22 \pm 0.25$ & $99.92 \pm 1.09$ \\
100\% $\pm(\%$ RSD) & $103.01 \pm 0.93$ & $102.02 \pm 0.76$ \\
120\% $\pm(\%$ RSD) & $100.95 \pm 0.68$ & $99.82 \pm 1.34$ \\
Specificity study & Percent drug remained \\
Acid stress & 95.94 & 82.29 \\
Base stress & 94.95 & 98.63 \\
Oxidation stress & 67.19 & 87.4 \\
Thermal stress & 92.28 & 91.27 \\
\hline
\end{tabular}

The assay results obtained has shown that the method is suitable for the routine analysis of CFFE and TAZO in their combined dosage form.

\subsection{Validation}

3.2.1. System Suitability. System suitability parameters of the developed HPLC method were determined (Table 2). The parameters like capacity factor, theoretical plates and asymmetry factor were within range of the specified limit.

3.2.2. Linearity Study. Linearity graph of working standard solution concentration versus peak area was plotted for CEFE and TAZO. The graph was found linear in the range of 4$24 \mu \mathrm{g} / \mathrm{mL}$ for CEFE and $0.5-3 \mu \mathrm{g} / \mathrm{mL}$ for TAZO (Table 2).

3.2.3. Precision. Precision of the method was verified by repeatability and intermediate precision study. Repeatability was measured by determining \% RSD of multiple injections of a homogenous sample of $12 \mu \mathrm{g} / \mathrm{mL}$ of CEFE and $1.5 \mu \mathrm{g} / \mathrm{mL}$ of TAZO which was found to be 0.92 and 1.09 , respectively. Intra-day precision was calculated by determining $\%$ RSD of analysis of 4,8 and $12 \mu \mathrm{g} / \mathrm{mL}$ of CEFE and $0.5,1.0$ and $1.5 \mu \mathrm{g} / \mathrm{mL}$ of TAZO on the same day which was found to be 0.51 and 0.29 respectively. Inter day precision was checked by repeating an analysis of the same concentrations of CEFE and TAZO on three different days having \% RSD of 0.27 and 
TABLE 3: Investigated range of experimental variables during robustness testing.

\begin{tabular}{lcc}
\hline Variable & Optimized value & Range investigated \\
\hline $\begin{array}{l}\text { Mobile phase } \\
\text { (Buffer/acetonitrile, v/v) }\end{array}$ & $94: 6$ & $93: 7-95: 5$ \\
Flow rate $(\mathrm{mL} / \mathrm{min})$ & 1.0 & $0.9-1.1$ \\
Wavelength $(\mathrm{nm})$ & 210 & $207-213$ \\
\hline
\end{tabular}

0.54 (Table 2). The \% RSD value less than 2 indicates that the developed method was a precise one.

3.2.4. Accuracy. To study the reliability, suitability and accuracy of the method recovery study was carried out by standard addition method at 80,100 and $120 \%$ of label claim. At each level, three determinations were carried out. The $\%$ RSD value of \% recovery was less 2 indicate that the developed method was accurate one (Table 2).

3.2.5. Sensitivity. The quantitation limit is a parameter of the quantitative assay at low levels of analyte in sample matrices and is used particularly for the determination of impurities and degradation products. LOD and LOQ were found to be $0.26 \mu \mathrm{g} / \mathrm{mL}$ and $0.80 \mu \mathrm{g} / \mathrm{mL}$ for CEFE and $0.020 \mu \mathrm{g} / \mathrm{mL}$ and $0.062 \mu \mathrm{g} / \mathrm{mL}$ for TAZO, respectively.

3.2.6. Specificity. Forced degradation study was performed to evaluate the specificity of the proposed method. Sample for degradation study was prepared by refluxing the CEFE solution at $70^{\circ} \mathrm{C}$ with $1 \mathrm{M} \mathrm{HCl}, 0.5 \mathrm{M} \mathrm{NaOH}$ and exposed to $5 \% \mathrm{w} / \mathrm{v} \mathrm{H}_{2} \mathrm{O}_{2}$ for $10 \mathrm{~min}$. For TAZO, solution was refluxed at $70^{\circ} \mathrm{C}$ with $0.01 \mathrm{M} \mathrm{HCl}, 0.01 \mathrm{M} \mathrm{NaOH}$ and exposed to $0.1 \% \mathrm{w} / \mathrm{v}$ $\mathrm{H}_{2} \mathrm{O}_{2}$ for $10 \mathrm{~min}$. In addition, the CEFE and TAZO solutions were subjected to thermal degradation as for CEFE at $105^{\circ} \mathrm{C}$ for $88 \mathrm{~h}$ and for $\mathrm{TAZO}$ at $105^{\circ} \mathrm{C}$ for $24 \mathrm{~h}$. After specified time, samples were removed, allowed to cool and diluted to the same concentration as the standard solution. The samples were analyzed by the optimized chromatographic conditions against a control sample. The result of degradation study has shown in Figures 3, 4 and Table 2.

No interference was found at the Rt of CEFE and TAZO. The peak purity value for CEFE and TAZO was found to be more than the threshold value confirms no interference of degradation products, impurity or any formulation excipient. Thus, the developed method was found to be a specific one.

3.2.7. Robustness. The HPLC method robustness was carried out by deliberate small variation in the flow rate, mobile phase composition and wavelength. The robustness study of HPLC method was carried out statistically by using Design Expert software. Robustness testing was performed in order to obtain information about critical parameters affecting the selected response (peak area, retention time and found concentration). Multivariate approach was utilized to study the effect of simultaneous variations of experimental variables on the selected responses.
A three factor face centered design (FCD) was employed to evaluate the effects of three independent factors, namely, the percentage of mobile phase $\left(X_{1}\right)$; flow rate $\left(X_{2}\right)$; and wavelength $\left(X_{3}\right)$ on peak area $\left(R_{1}\right)$, retention time $\left(R_{2}\right)$ and found concentration $\left(R_{3}\right)$. The investigated range of experimental variables has shown in Table 3.

The coefficients of the second order polynomial model were estimated by the least squares regression. The model equation for CEFE and TAZO for selected response $R$ was as follows:

$$
\begin{aligned}
R= & 9.162 E+005+10738.40 X_{1}-28458.00 X_{2} \\
& -53886.20 X_{3}+8109.25 X_{1} X_{2}-15290.50 X_{1} X_{3} \\
& -9273.50 X_{2} X_{3}+9523.15 \times X_{1}^{2}-11445.85 \times X_{2}^{2} \\
& -21314.85 \times X_{3}^{2}, \\
R= & 75690.56+522.10 X_{1}-3597.10 X_{2}-5487.70 X_{3} .
\end{aligned}
$$

From the experimental response, it was found that an increase in wavelength causes decrease in mean peak area (and found concentration), while the organic modifier had no such effect in case of CEFE and TAZO. As flow rate decreases, the retention time of CEFE and TAZO becomes longer. So, a precautionary statement about wavelength is to be included in procedure.

\section{Discussion}

The RP-HPLC method has been developed for the simultaneous determination of CEFE and TAZO in bulk and pharmaceutical dosage form.

TAZO has UV absorption below $210 \mathrm{~nm}$. As below $210 \mathrm{~nm}$, the molecular oxygen and absorption of solvent will interfere in quantitative analysis. The TAZO estimation by UV spectroscopy was found to be difficult. Therefore, RPHPLC method was developed for simultaneous estimation of CEFE and TAZO in bulk and pharmaceutical dosage form. Advantages of proposed HPLC method were as simple, easy mobile phase preparation, run time $<12 \mathrm{~min}$ and economical one.

A buffer concentration of $25 \mathrm{mM}$ phosphate buffer was used in mobile phase as it is a good compromise. At higher buffer concentrations $(>50 \mathrm{mM})$ provide increased buffer capacity but may not be soluble in the mobile phase [29]. Higher buffer concentration also may adversely affect the operation of HPLC system constructed of stainless steel [29]. The phosphate, one of inorganic buffer is marginally soluble in a solution containing a high concentration of organic. The phosphate buffer used for controlling $\mathrm{pH}$ in the range 2.1 to 3.1 or 6.2 to 8.2 allows detection at $210 \mathrm{~nm}$ or lower [29].

Acetonitrile was the preferred component in mobile phase as it allows the quantitative measurements below $210 \mathrm{~nm}$.

It is evident from a system suitability test that the method developed for CEFE and TAZO combination had passed the standards of regulatory requirements. 


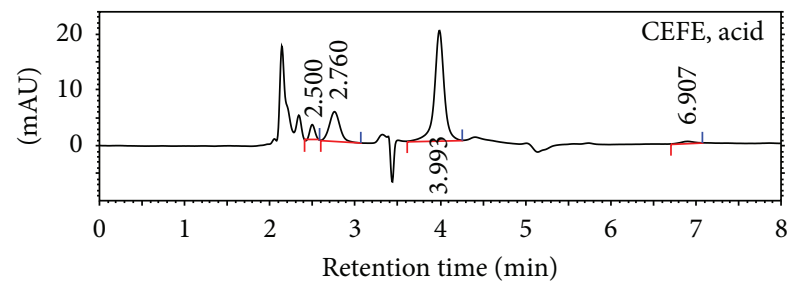

(a)

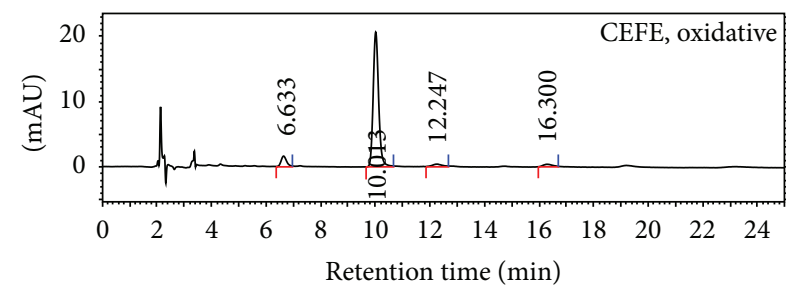

(c)

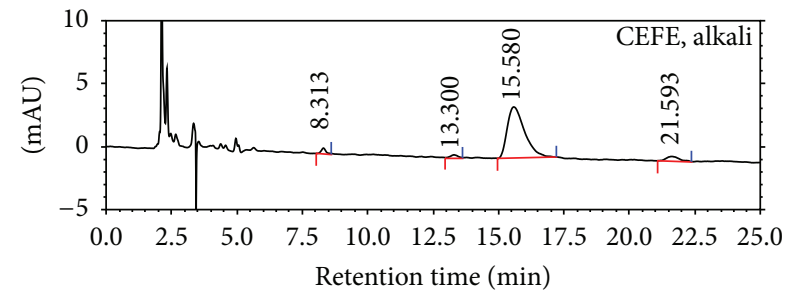

(b)

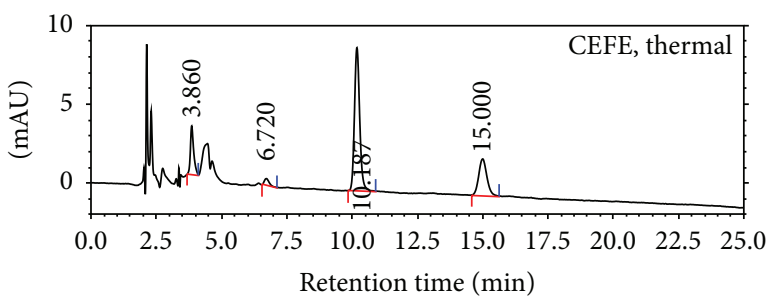

(d)

FIGURE 3: Chromatogram of specificity study of CEFE ((a) acid stress (b) alkali stress (c) oxidative stress and (d) thermal stress).

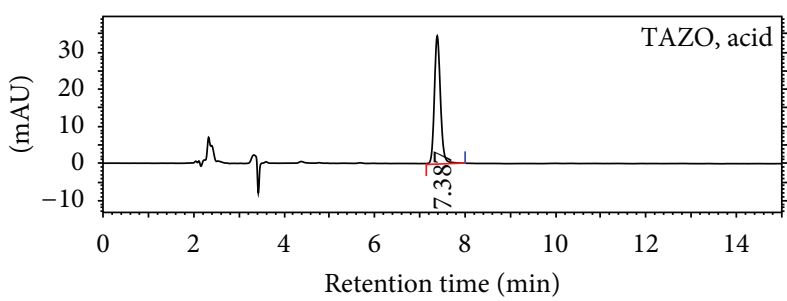

(a)

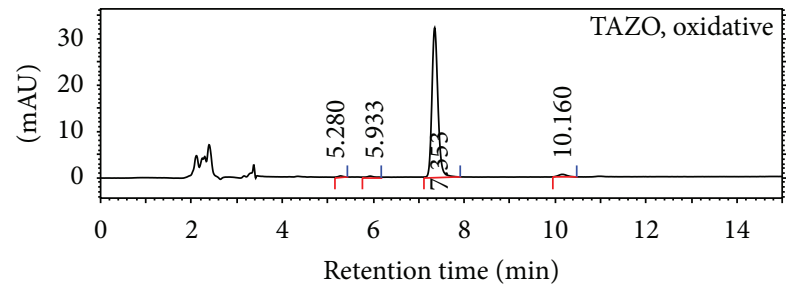

(c)

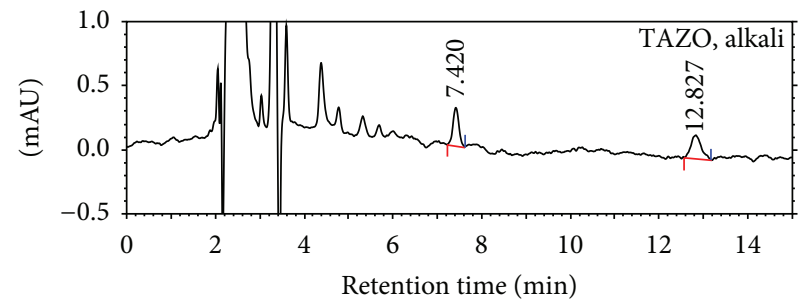

(b)

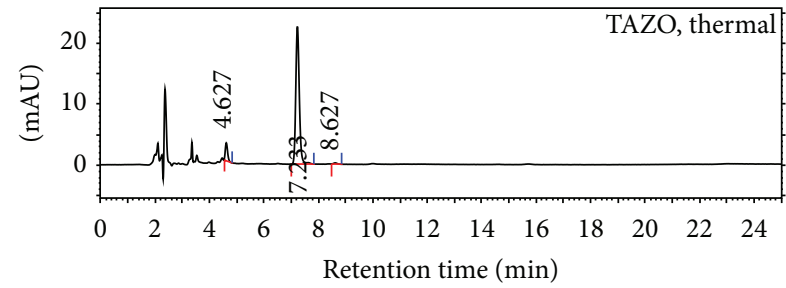

(d)

FIGURE 4: Chromatogram of specificity study of TAZO ((a) acid stress (b) alkali stress (c) oxidative stress and (d) thermal stress).

The method was found to be linear over the wide range and to be useful for bulk and pharmaceutical analyses. The method was successfully applied to bulk material and pharmaceutical formulation assay. From specificity study, it was observed that drug combination is free from excipient interaction and method is suitable for analysis of CEFE and TAZO in the presence of their degradation products or impurity. According to ICH Q2 (R1) guideline, the robustness of an analytical procedure refers to its capability to remain unaffected by small and deliberate variation in method parameters. All the 18 experimental runs suggested by the design expert software were performed in randomized order to minimize the effects of uncontrolled factors that may introduce a bias in response. Experimental results were computed using Design-Expert version 8.0.6 software [28]. From the results of robustness study it was observed that the proposed method was found to be robust when deliberate variations were made in the optimized chromatographic conditions.

\section{Conclusion}

The proposed RP-HPLC method is simple, rapid, precise, accurate and robust for the simultaneous estimation of CEFE and TAZO in bulk and its injection formulation. Hence, it can be conveniently adopted for the routine quality control analysis.

\section{Conflict of Interests}

The authors of the paper do not have a direct financial relation with the commercial identity mentioned in the paper. The 
authors report no declaration of interests and do not have any conflict of interests.

\section{References}

[1] D. Hurum, B. De Borba, and J. Rohrer, "Assaying the concentration of cefepime by HPLC with UV detection," LC GC North America, vol. 27, no. 2, p. 48, 2009.

[2] I. N. Valassis, M. Parissi-Poulou, and P. Macheras, "Quantitative determination of cefepime in plasma and vitreous fluid by highperformance liquid chromatography," Journal of Chromatography B, vol. 721, no. 2, pp. 249-255, 1999.

[3] N. Cherti, J.-M. Kinowski, J. Y. Lefrant, and F. Bressolle, "High-performance liquid chromatographic determination of cefepime in human plasma and in urine and dialysis fluid using a column-switching technique," Journal of Chromatography B, vol. 754, no. 2, pp. 377-386, 2001.

[4] Y. L. Chang, M. H. Chou, M. F. Lin, C. F. Chen, and T. H. Tsai, "Determination and pharmacokinetic study of unbound cefepime in rat bile by liquid chromatography with on-line microdialysis," Journal of Chromatography A, vol. 914, no. 1-2, pp. 77-82, 2001.

[5] P. F. Sprauten, P. M. Beringer, S. G. Louie, T. W. Synold, and M. A. Gill, "Stability and antibacterial activity of cefepime during continuous infusion," Antimicrobial Agents and Chemotherapy, vol. 47, no. 6, pp. 1991-1994, 2003.

[6] S. M. Rabouan-Guyon, A. F. Guet, P. Y. Courtois, and D. M. C. Barthes, "Stability study of cefepime in different infusion solutions," International Journal of Pharmaceutics, vol. 154, no. 2, pp. 185-190, 1997.

[7] B. Uslu, S. A. Ozkan, and P. Zuman, "Contribution to the alkaline degradation of cefepime," Microchemical Journal, vol. 76, no. 1-2, pp. 61-63, 2004.

[8] V. Jagadeesh Kumar, P. Badarinadh Gupta, K. S. R. Pavan Kumar et al., "Identification and characterization of new degradation products of cefepime dihydrochloride monohydrate drug substance during stress stability studies," Analytical Sciences, vol. 26, no. 10, pp. 1081-1086, 2010.

[9] J. O. Fubara and R. E. Notari, "Influence of $\mathrm{pH}$, temperature and buffers on cefepime degradation kinetics and stability predictions in aqueous solutions," Journal of Pharmaceutical Sciences, vol. 87, no. 12, pp. 1572-1576, 1998.

[10] M. Siddiqui, A. Tariq, K. Reddy et al., "High performance liquid chromatographic method for simultaneous determination of cefepime and sulbactam in pharmaceutical formulation (Supime) and biological samples," International Journal of Pharmacology, vol. 6, no. 3, pp. 271-277, 2010.

[11] H. Elkhaili, L. Linger, H. Monteil, and F. Jehl, "Highperformance liquid chromatographic assay for cefepime in serum," Journal of Chromatography B, vol. 690, no. 1-2, pp. 181$188,1997$.

[12] K. J. V. López, D. F. Bertoluci, K. M. Vicente, A. M. Dell’Aquilla, and S. R. C. J. Santos, "Simultaneous determination of cefepime, vancomycin and imipenem in human plasma of burn patients by high-performance liquid chromatography," Journal of Chromatography B, vol. 860, no. 2, pp. 241-245, 2007.

[13] M. Ip, C. Au, S. W. Cheung, C. Y. Chan, and A. F. B. Cheng, "A rapid high-performance liquid chromatographic assay for cefepime, cefpirome and meropenem," Journal of Antimicrobial Chemotherapy, vol. 42, no. 1, pp. 121-123, 1998.

[14] D. Breilh, C. Lavallee, A. Fratta, D. Ducint, P. Cony-Makhoul, and M. C. Saux, "Determination of cefepime and cefpirome in human serum by high-performance liquid chromatography using an ultrafiltration for antibiotics serum extraction," Journal of Chromatography B, vol. 734, no. 1, pp. 121-127, 1999.

[15] "In Determination of N-methylpyrrolidine in cefepime using a reagent free ion chromatography system," Dionex application notes 199, http://www.dionex.com/en-us/index.html.

[16] In Dionex: Application note 259, http://www.dionex.com/ en-us/index.html.

[17] W. Long, "In Application note pharmaceuticals, Agilent technologies," 2011, http://www.home.agilent.com/agilent/home .jspx?cc=US\&lc=eng.

[18] "In Dionex: Application note 205," http://www.dionex.com/ en-us/index.html.

[19] M. Dave Vimal, "Development and validation of Rp-Hplc method for simultaneous estimation of cefepime hydrochloride and amikacin sulphate in injection dosage form," Journal of Pharmaceutical Science and Bioscience Research, vol. 2, no. 2, pp. 58-62, 2012.

[20] A. L. Rao, K. Krishna, C. K. Kumar, and T. Raja, "Simultaneous determination of piperacillin and tazobactum in bulk and pharmaceutical dosage forms by RP-HPLC,' System 1, 0.0062, 2011.

[21] V. Augey, P.-Y. Grosse, G. Albert, M. Audran, and F. Bressolle, "High-performance liquid chromatographic determination of tazobactam and piperacillin in human plasma and urine," Journal of Chromatography B, vol. 682, no. 1, pp. 125-136, 1996.

[22] M. Gandhimathi, M. Saravanakumar, and T. K. Ravi, "Validated ion pair HPLC method for simultaneous estimation of ceftriaxone sodium and tazobactum sodium in dosage form," International Journal of Pharma \& Bio Sciences, vol. 1, no. 4, article 3, 2010.

[23] R. N. Kumar, G. N. Rao, and P. Naidu, "Stability indicating fast lc method for determination of ceftriaxone and tazobactam for injection related substances in bulk and pharmaceutical formulation," International Journal of Applied Biology and Pharmaceutical Technology, vol. 1, no. 1, pp. 145-157, 2010.

[24] Y. Guillaume, E. Peyrin, and C. Guinchard, "Rapid determination of sulbactam and tazobactam in human serum by highperformance liquid chromatography," Journal of Chromatography B, vol. 665, no. 2, pp. 363-371, 1995.

[25] P. N. S. Pai, G. K. Rao, M. S. Murthy, and H. Prathibha, "Simultaneous estimation of piperacillin and tazobactam in injection formulations," Indian Journal of Pharmaceutical Sciences, vol. 68, no. 6, pp. 799-801, 2006.

[26] A. P. Ocampo, K. D. Hoyt, N. Wadgaonkar, A. H. Carver, and C. V. Puglisi, "Determination of tazobactam and piperacillin in human plasma, serum, bile and urine by gradient elution reversed-phase high-performance liquid chromatography," Journal of Chromatography, vol. 496, no. 1, pp. 167-179, 1989.

[27] ICH Guidelines, Validation of Analytical Procedures: Text and Methodology, IFPMA, Geneva, Switzerland, 2005.

[28] R. Ficarra, M. L. Calabrò, P. Cutroneo et al., "Validation of a LC method for the analysis of oxaliplatin in a pharmaceutical formulation using an experimental design," Journal of Pharmaceutical and Biomedical Analysis, vol. 29, no. 6, pp. 1097-1103, 2002.

[29] L. R. Snyder, J. J. Kirkland, and J. L. Glajch, Practical HPLC Method Development, Wiley Interscience, New York, NY, USA, 1997. 

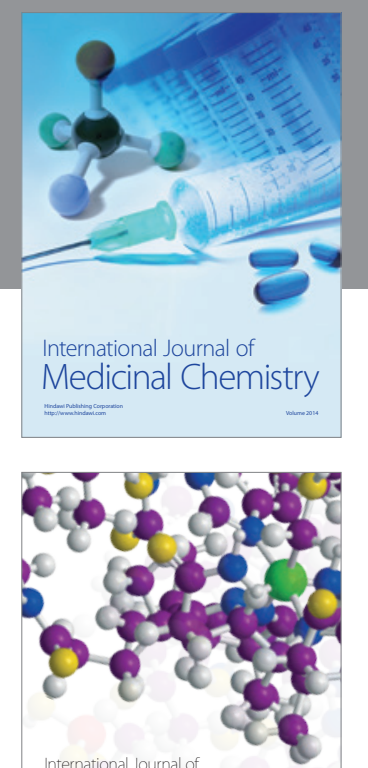

\section{Carbohydrate} Chemistry

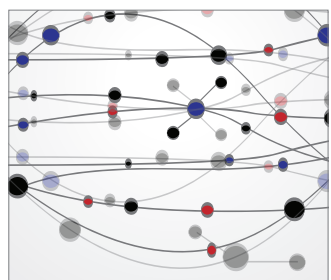

The Scientific World Journal
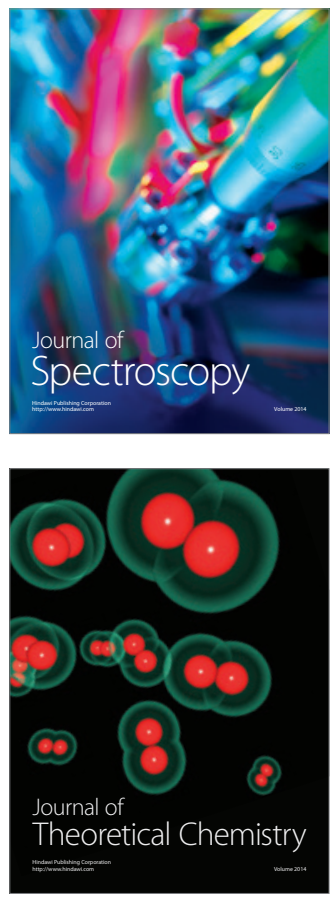
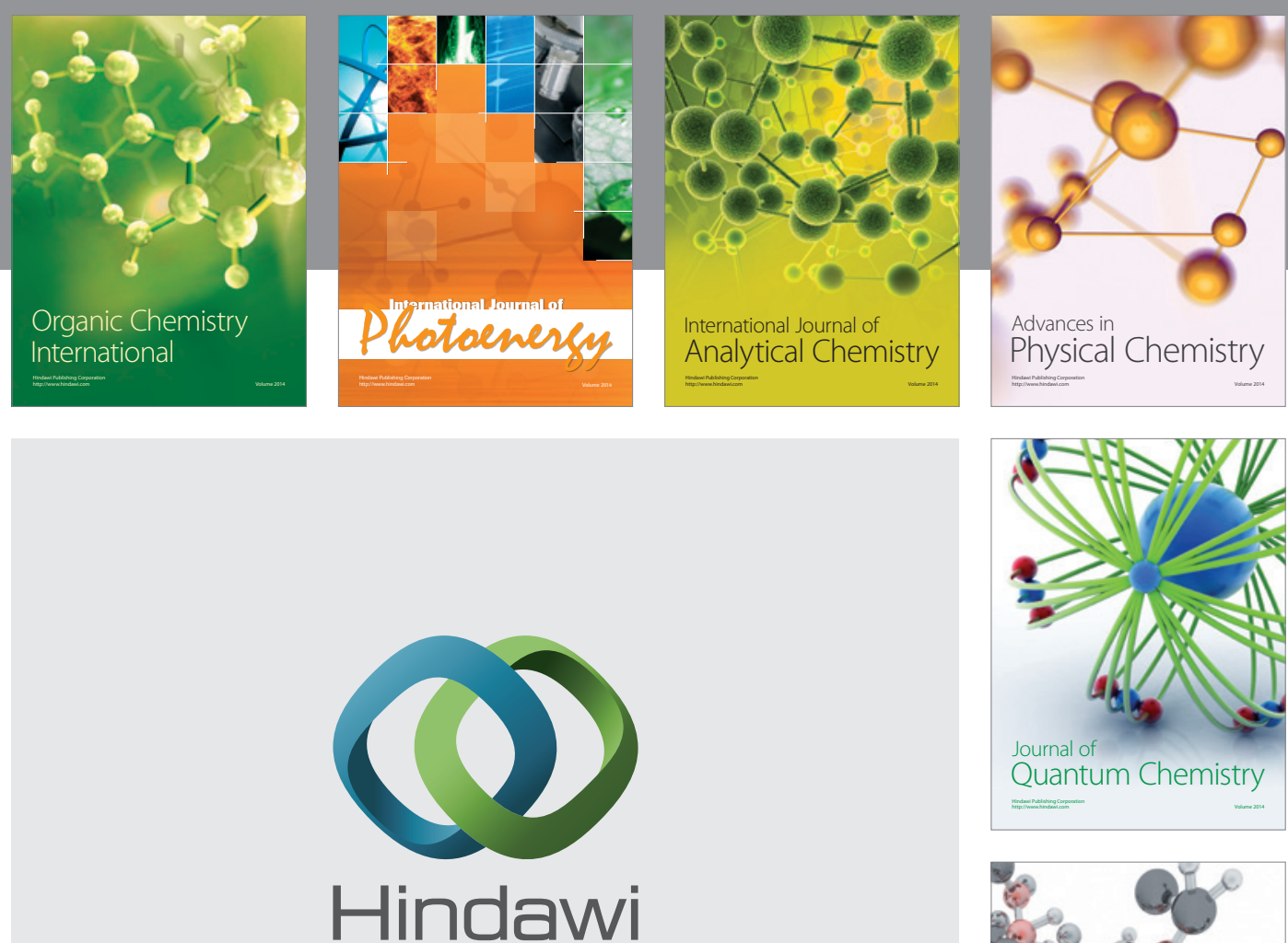

Submit your manuscripts at

http://www.hindawi.com

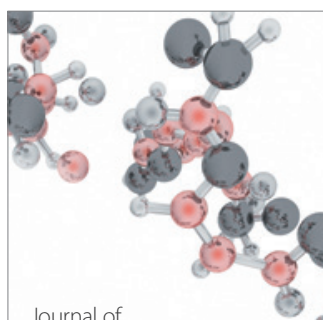

Analytical Methods

in Chemistry

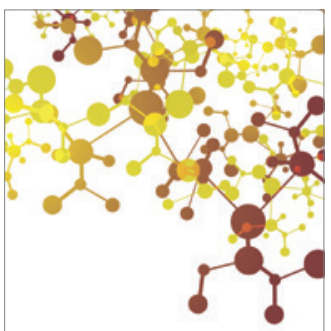

Journal of

Applied Chemistry

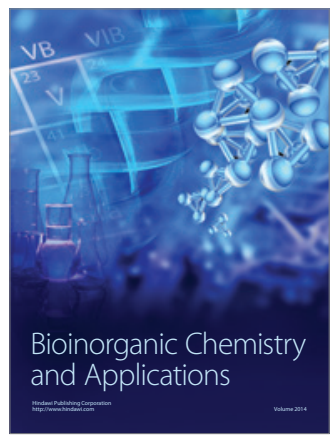

Inorganic Chemistry
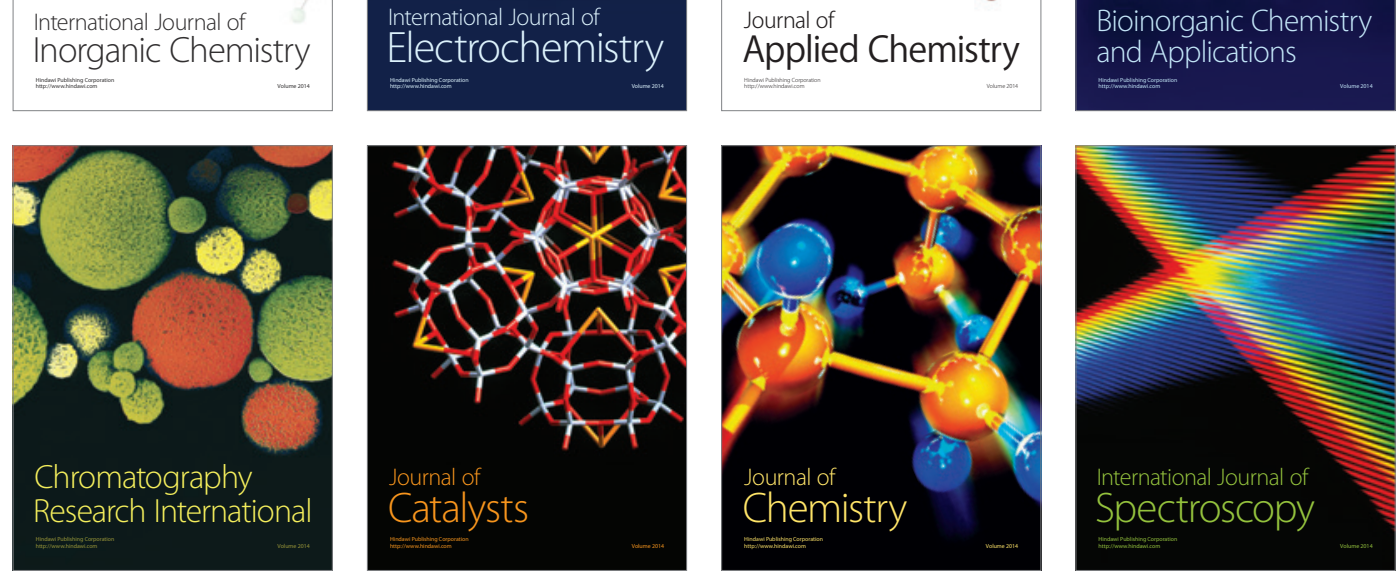